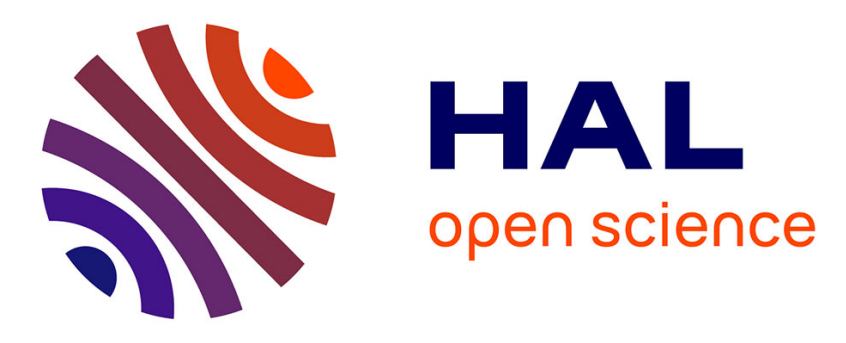

\title{
Influence of the formulation of an alumina powder on compaction
}

David Souriou, Patrice Goeuriot, Olivier Bonnefoy, Gérard Thomas, Florence

Doré

\section{- To cite this version:}

David Souriou, Patrice Goeuriot, Olivier Bonnefoy, Gérard Thomas, Florence Doré. Influence of the formulation of an alumina powder on compaction. Powder Technology, 2009, 190 (1-2), pp.152-159. 10.1016/j.powtec.2008.04.074 . hal-00410221

\section{HAL Id: hal-00410221 \\ https://hal.science/hal-00410221}

Submitted on 18 Aug 2009

HAL is a multi-disciplinary open access archive for the deposit and dissemination of scientific research documents, whether they are published or not. The documents may come from teaching and research institutions in France or abroad, or from public or private research centers.
L'archive ouverte pluridisciplinaire HAL, est destinée au dépôt et à la diffusion de documents scientifiques de niveau recherche, publiés ou non, émanant des établissements d'enseignement et de recherche français ou étrangers, des laboratoires publics ou privés. 


\title{
Influence of the formulation of an alumina powder on compaction
}

\author{
D. SOURIOU(1) , P. GoEURIOT(1), O. BonNEFOY(2, *), G. ThOMAS(2) , F. DORE (3)
}

(1) Département MPE (Mécanique et Procédés d'Elaboration), Centre SMS - PECM UMR CNRS 5146. Ecole Nationale Supérieure des Mines de Saint-Etienne. 158, Cours Fauriel. 42023 Saint-Etienne Cedex 2.

(2) Département PMMC (Poudres et Matériaux Multi Composants), Centre SPIN - LPMG UMR CNRS 5148. Ecole Nationale Supérieure des Mines de Saint-Etienne. 158, Cours Fauriel. 42023 Saint-Etienne Cedex 2.

(3) CETIM, 7 Rue de la Presse, BP802, 42952 Saint Etienne Cedex o9, France

(*) obonnefoy@emse.fr

keywords:

Compression; Alumina; Formulation; High Velocity Compaction; Phenomenology

\begin{abstract}
The compression of ceramic powders requires the addition of organic materials to insure tablet cohesion. For the compaction of formulated ceramic powders it is necessary to supply them energy. As a function of the formulation of ceramic powders, one can measure the specific energy acquired during the tablet compression. Recently, a technique used in powder metallurgy, High Velocity Compaction (HVC), has been studied to form ceramic compacts. This method brings special physical properties to tablets in terms of homogeneity compared to conventional uniaxial pressing. The properties of tablets prepared by the two processes are compared and discussed through a phenomenological model.
\end{abstract}

\section{Introduction}

Quasi-static uniaxial pressing (or conventional pressing) is a standard method in ceramic manufacture. The aim is to make cohesive compacts as dense as possible. But the cohesion between ceramic grains is really not insured by surface forces only, and organic materials that act as a glue between ceramic grains are added. The behaviour of the powder during compression and the physical properties of the compact may vary, depending on the formulation of this "glue", in particular the green density and mechanical resistance.

A new forming method for powders, High Velocity Compaction (HVC), has been used to make metallic and ceramic compacts [1], [2], [3], [4], [5], [6], [7] and [8]. The HVC device is a HYDROPULSOR press. This technique is similar to conventional pressing but consists in accelerating a ram. That ram strikes the upper punch of the die with a given kinetic energy and the stress increases in a very short time $\left(t<3 \cdot 10^{-4} \mathrm{~s}\right)$ compared to conventional pressing. Initial studies with alumina powders have shown that higher stresses (greater than $1 \mathrm{GPa}$ ) could be reached and that the final tablets were more homogeneous [9]. Computer simulations of HVC have been performed by some authors [10] and [11] and a comparative study of conventional pressing and HVC has been done for various materials [12] and [13]. The aim of this study is to understand the influence of the powder formulation and of the forming method on tablets properties and then to compare the compaction behaviours of a powder bed submitted to each of the forming processes.

\section{Experimental procedure}

\section{Materials}

Different spray-dried powders have been made and supplied by Baikowski S.A. in order to test the influence of crystallite sizes and of organic formulations on compact properties. Two kinds of commercial alumina are used: SM8 alumina (mean volumetric crystallite size $d_{43}=0.4 \mu \mathrm{m}$ ) and B15 alumina (mean volumetric crystallite size $d_{43}=0.15 \mu \mathrm{m}$ ). Alumina is chosen for its 
mechanical and rheological properties (no viscous-like deformation at ambient temperature). Its density is $3.986 \mathrm{~g} \mathrm{~cm}^{-3}$ [14]. The choice of powder formulation is based on a typical plasticizer (PEG 4000) and mixtures of a binder (PVA) and a softer plasticizer (PEG 1500).

These water-soluble formulations have been chosen because of their frequent use in industry. They are dissolved in a suspension of alumina that is spray-dried after their dissolution and then the granules obtained are composed of "shells" containing ceramic particles embedded in a porous polymeric matrix [15].

Table 1 shows the different denominations given to 10 spray-dried industrial powders. The mean volumetric spray-dried granule size of alumina coated with organic material $d_{43}: 20 \mu \mathrm{m}$. The number, 2 or 4, refers to the mass percentage of organic material with respect to alumina mass. P letter refers to plasticizers, L letter to binders. When organic formulations contain a binder and a plasticizer, the first letter refers to the substance appearing with the heaviest part. The global density of powders is calculated by taking into account the organic phase.

Table 1: SM8 and B15 alumina powder formulations and nomenclatures

\begin{tabular}{|c|c|c|c|c|c|c|c|c|c|c|}
\hline Denomination & SM8-2P & SM8-4P & $\begin{array}{l}\text { SM8- } \\
2 \mathrm{~L} / \mathrm{P}\end{array}$ & $\begin{array}{l}\text { SM8- } \\
4 \mathrm{~L} / \mathrm{P}\end{array}$ & $\begin{array}{l}\text { SM8- } \\
2 \mathrm{P} / \mathrm{L}\end{array}$ & $\begin{array}{l}\text { SM8- } \\
4 \mathrm{P} / \mathrm{L}\end{array}$ & $\mathrm{B} 15-2 \mathrm{P}$ & $\mathrm{B} 15-4 \mathrm{P}$ & $\begin{array}{l}\text { B15- } \\
2 \mathrm{~L} / \mathrm{P}\end{array}$ & $\begin{array}{l}\mathrm{B} 15- \\
4 \mathrm{~L} / \mathrm{P}\end{array}$ \\
\hline $\begin{array}{c}\text { Alumina } \\
\text { crystallite } \\
\text { diameter } \\
(\mu \mathrm{m})\end{array}$ & 0.4 & 0.4 & 0.4 & 0.4 & 0.4 & 0.4 & 0.15 & 0.15 & 0.15 & 0.15 \\
\hline $\begin{array}{c}\text { Amount of } \\
\text { organic } \\
\text { additions (\%) }\end{array}$ & 2 & 4 & 2 & 4 & 2 & 4 & 2 & 4 & 2 & 4 \\
\hline Binder & - & - & PVA & PVA & PVA & PVA & - & - & PVA & PVA \\
\hline $\begin{array}{c}\text { Binder } \\
\text { proportion } \\
(\%)\end{array}$ & O & O & 66 & 66 & 33 & 33 & $\mathrm{O}$ & $\mathrm{O}$ & 66 & 66 \\
\hline $\begin{array}{l}\text { Plasticizer } \\
\text { proportion } \\
(\%)\end{array}$ & 100 & 100 & 33 & 33 & 66 & 66 & 100 & 100 & 33 & 33 \\
\hline
\end{tabular}

\section{HVC device}

The HVC device is shown in Fig. 1. Compaction energy is given by the fall on the upper punch of a $350 \mathrm{~kg}$ ram, accelerated by hydraulic pressure over a maximum distance of $160 \mathrm{~mm}$. This device is able to strike 5 times per second with a control of the delivered energy at each shot (maximum deliverable energy: $20 \mathrm{~kJ}$ ). Compacts are formed in a $50 \mathrm{~mm}$ diameter cylindrical die made of cemented tungsten carbide (WC-Co).

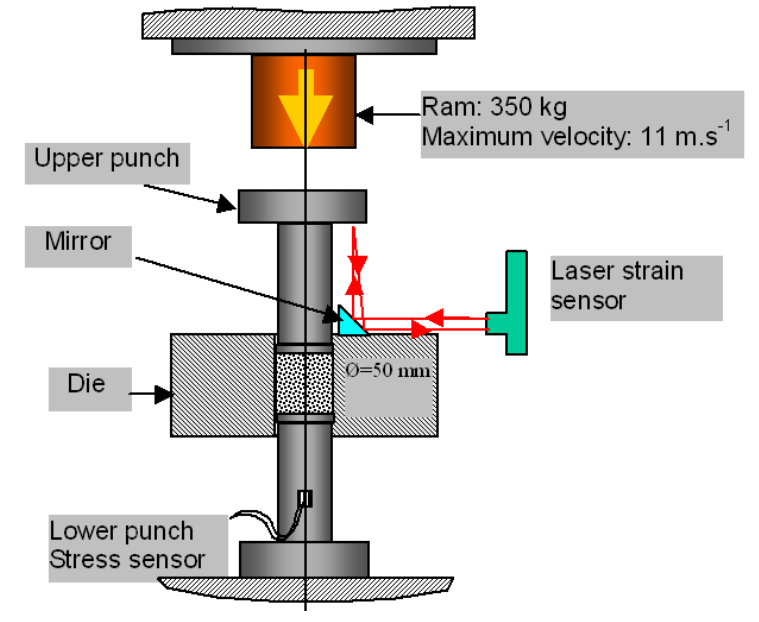

Fig. 1: Schematic of HVC device.

A stress sensor is placed under the lower punch. The upper punch displacement can be detected via a laser beam reflected by a mirror. It is then possible to get useful data and to 
draw stress-displacement curves. Displacement during the impact and the stress signal are followed through data acquisition at high frequency $(10 \mathrm{kHz})$. Filling the die with $70 \mathrm{~g}$ of alumina powder leaves a sufficient distance between the upper punch and the mirror after impact, thus avoiding damage in the experiment. A precompression of $60 \mathrm{MPa}$ is applied before each impact, so that a great part of the air contained in the powder bed is eliminated and a defectless compact can be obtained. The displacement during the impact and the stress signal are followed through data acquisition at high frequency $(10 \mathrm{kHz})$.

Conventional pressing

Conventional compacts are elaborated in an INSTRON traction-compression press, in a carbide $20 \mathrm{~mm}$ diameter cylindrical die. In the conventional device $3 \mathrm{~g}$ of powder are introduced in the die and first pre-compressed at $60 \mathrm{Mpa}$, then compressed at $400 \mathrm{MPa}$ in order to compare conventional compacts with HVC compacts.

\section{HVC compacts}

For each HVC experiment, a precompression of $60 \mathrm{MPa}$ is applied before each impact, so that a great part of the air contained in the powder bed is eliminated and a defectless compact can be obtained. Then a strike energy of $2950 \mathrm{~J}$ is applied to $70 \mathrm{~g}$ of powder, so that the forming pressure is close to $400 \mathrm{MPa}$. Compacts of approximately $50 \mathrm{~mm}$ diameter and $15 \mathrm{~mm}$ height are obtained.

Fig. 2 gives an example of stresses and displacements measured during HVC experiments as a function of time in the case of SM8-4L/P powder. The successive peaks of stress and strain appear to be simultaneous. They may correspond to successive shock wave reflections (as noticed by Azhdar et al. [12]). Only the first stress peak (or main stress peak) will be considered as the forming HVC pressure.

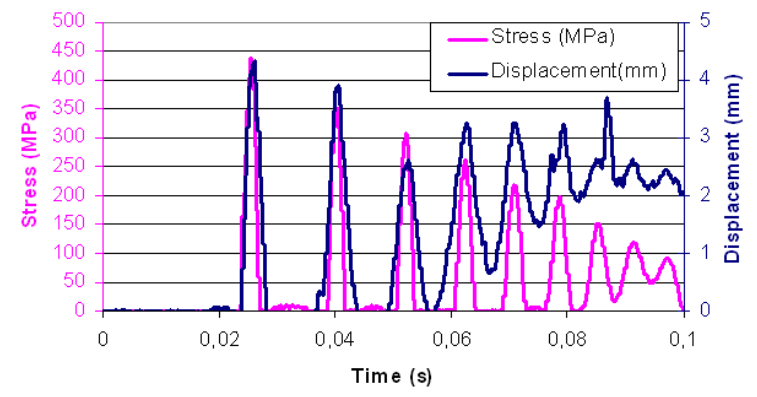

Fig. 2: Stress and displacement evolution during a HVC experiment.

It is necessary to add a binder to make HVC compacts, this is because powder compacts formulated with a plasticizer are found to have only material defects such as loss of material or they break after ejection. Powders with $2 \%$ of a binder/plasticizer mixtures give compacts that present random results in terms of quality; some are broken; others have no defects. Finally, all compacts prepared with a powder containing $4 \%$ of a binder/plasticizer mixture give compacts without defect.

Conventional compact forming

For each conventional experiment, $3 \mathrm{~g}$ of powder are firstly pre-compressed at $60 \mathrm{MPa}$ and then compressed at $400 \mathrm{MPa}$ with a constant upper punch velocity of $10 \mathrm{~mm} \mathrm{~min} \mathrm{~m}^{-1}$. Compacts of approximately $20 \mathrm{~mm}$ diameter and $4 \mathrm{~mm}$ height are obtained and may be compared to HVC compacts.

All powders except SM8-2P lead to compacts without defect. This shows that formulations adapted to conventional pressing may be inadapted to HVC.

Conventional and HVC stress comparison

During HVC experiments, stresses are recorded through the stress sensor located under the lower punch. In conventional experiments, stresses are detected at the top of the upper punch. To link the results from experiments carried out in these two processes, let us consider the Shaxby, Evans and Unkel equation between upper and lower stresses [16]: 
$\ln \frac{\sigma_{\text {sup }}}{\sigma_{\text {inf }}}=\frac{2 H}{R} \mu \beta$

With $\sigma_{\text {sup }}$ the upper stress, $\sigma_{\text {inf }}$ the lower stress, $H$ the compact height, $R$ the compact radius, $\mu$ the wall-material friction coefficient (typically equal to o.1) and $\beta$ the stress transmission coefficient (typically equal to 0.5).

There is a difference of $6 \%$ between the upper and the lower stress in HVC experiments and $4 \%$ in conventional experiments. Taking into account the applied stresses, samples formed by HVC or conventional pressing with the same powder can be reasonably compared in terms of stress gradients, equivalent height/diameter ratio and highest stress reached during compaction.

\section{Compressibility curves}

For conventional pressing, there is first a precompaction of $60 \mathrm{MPa}$ followed by a relaxation. The powder bed is then further compacted at $400 \mathrm{MPa}$. Despite the two-step compaction, there is continuity in the stress-displacement curve. Thus the data recorded from o to $60 \mathrm{MPa}$ and then from $60 \mathrm{MPa}$ to $400 \mathrm{MPa}$ allow us to estimate the powder behaviour from $\mathrm{o}$ to $400 \mathrm{MPa}$. Fig. 3 shows the shape of curves obtained during the precompaction of $60 \mathrm{MPa}$ (blue curve) followed by the compression of $400 \mathrm{Mpa}$ (pink curve).

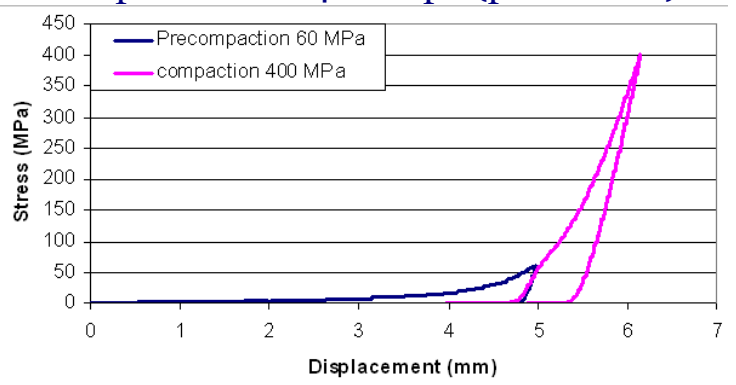

Fig. 3: Stress-displacement curves of a conventional precompaction of $60 \mathrm{MPa}$ followed by a compaction of $400 \mathrm{MPa}$.

Fig. 4 shows typical stress-displacement curves obtained for a conventional (a) and a HVC (b) experiment. For HVC, the stress-displacement curve is similar to the conventional one.

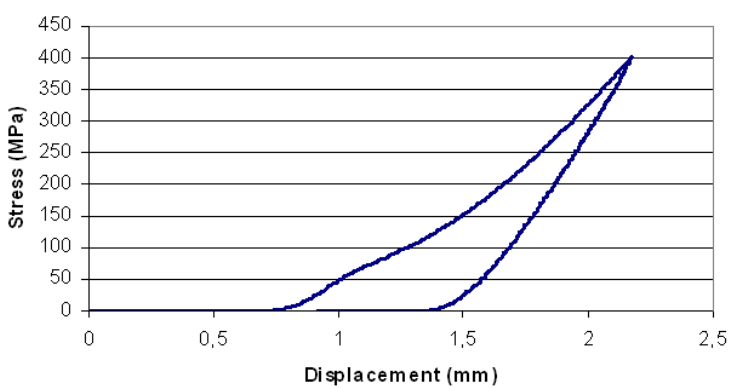

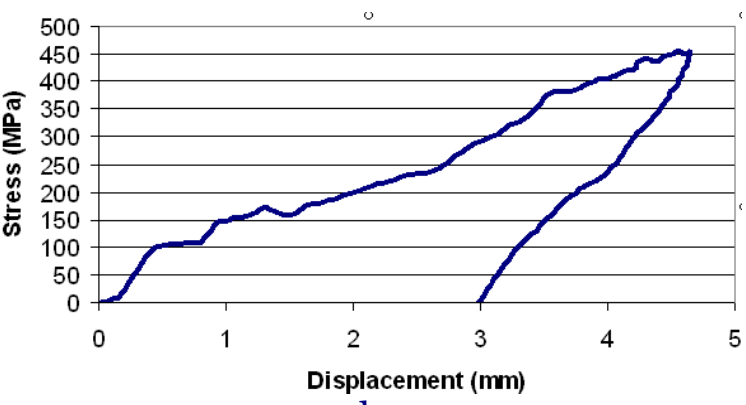

$\mathrm{b}$

Fig. 4: Stress-displacement curve in: (a), conventional pressing; (b), HVC (after precompaction).

Energy calculation

The conventional and HVC compressibility (stress-strain) curves are sketched in Fig. 5 . 


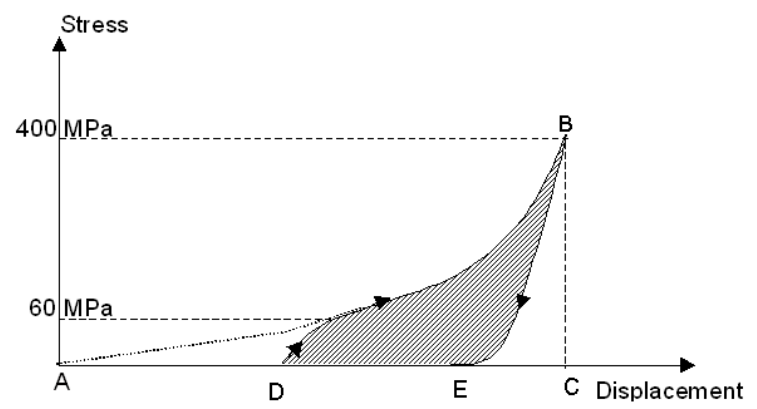

a

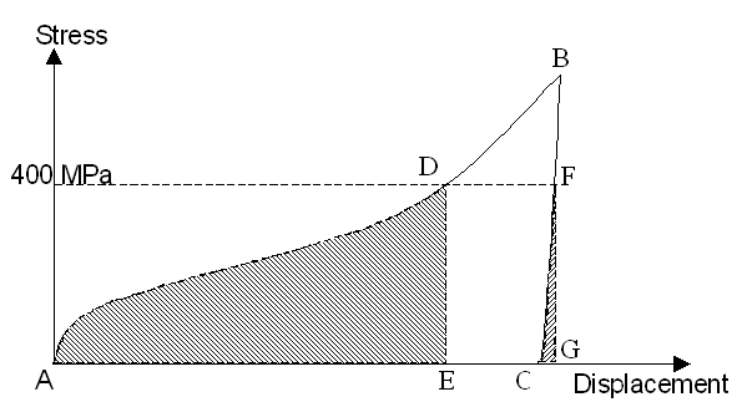

$\mathrm{b}$

Fig. 5: Schematic stress-displacement curve obtained after a precompaction of 60 MPa followed by a 400 MPa compaction. (a) Conventional stored energy is determined by calculation of the hatched surface (DBA). (b) HVC stored energy is calculated by the difference between ADE area (supplied energy) and FGC area (released energy).

Calculating the surface of the shaded grey area gives an estimation of the energy stored by the powder bed during the second compression at $400 \mathrm{MPa}$. In the case of conventional experiments, the energy supplied is calculated by integration of the compression curve from point $\mathrm{D}$ to point $\mathrm{B}$ (Fig. 5a). The energy released is calculated by integration of the compression curve from point B to point $\mathrm{E}$. The difference in the energy supplied and released gives the stored energy. Dividing the stored energy by the powder mass gives the specific stored energy. Many authors [17], [18], [19] and [20] have tackled this subject.

In case of HVC experiments, the forming pressure can exceed $400 \mathrm{MPa}$, so the energy supplied and released calculated between $\mathrm{o}$ and $400 \mathrm{MPa}$. The energy supplied is calculated by integration of the compression curve from point A to point D (Fig. 5b). The energy released is calculated by integration of the compression curve from point $\mathrm{F}$ to point $\mathrm{C}$. This allows us to estimate the specific energy that a HVC compact would store if its forming pressure were $400 \mathrm{MPa}$. Then, the specific stored energies for a given powder can be compared between the two forming methods.

\section{Mechanical resistance tests}

The mechanical resistance of a compact depends on the cohesion between spray-dried particles. This value is interesting because it allows us to decide if a piece can be manufactured or not. The mechanical resistance can be measured by a radial mechanical resistance test, called "Brazilian test", which consists in a radial pressing of a compact between two walls. The rupture force $F_{\text {rd }}$ is measured and the rupture stress $\sigma_{\text {rd }}$ can be calculated with the following equation [21]:

$\sigma_{r d}=\frac{2 . F_{r d}}{\pi \cdot \phi \cdot h_{f}}$ with $h_{f}$ the compact height and $\phi$ the compact diameter

The device used is a VARIAN VK200 tablet hardness tester.

\section{Mercury intrusion porosimetry (M.I.P.)}

For analysis, the compacts are previously debinded at $600{ }^{\circ} \mathrm{C}$ for $1 \mathrm{~h}$ with a heating rate and a cooling rate of $1^{\circ} \mathrm{C} \mathrm{min}{ }^{-1}$. The pore size distribution is then determined by mercury intrusion porosimeter (M.I.P.) (Autopore IV from MICROMERITICS).

Quasi-chemical model

The modelling of compression processes aims at expressing the volume variation of a compact as a function of applied pressure. The classical models are those proposed by Walker or Maxwell, but more recent models, such as Sonnergaard's [22] or Heckel-Gonthier's model [23], are suitable to explain fragmentation phenomena that are likely to occur during compaction of ceramic powders. The more recent Lamy-Thomas' model[24], is a phenomenological model that considers powder compression as a first order chemical 
reaction, where pores are eliminated as pressure increases. This quasi-chemical model can be expressed by the following equation:

$$
\frac{\varepsilon}{1-\varepsilon}=\frac{\varepsilon_{0}}{1-\varepsilon_{0}} \cdot\left[\frac{\varphi}{k_{f}+k_{C N}} \cdot\left(k_{C N}+\frac{k_{f} \cdot \psi}{\psi-k_{f}-k_{C N}}\right) \cdot e^{-\left(k_{f}+k_{C N}\right) \cdot P}+\left(1-\varphi-\frac{k_{f} \cdot \varphi}{\psi-k_{f}-k_{C N}}\right) \cdot e^{-\psi \cdot P}\right]
$$

* $\varepsilon$ (no unit): porosity of the granular packing at pressure $P, \varepsilon_{0}$ : initial porosity including initial intraparticular porosity $\left(\varepsilon_{\mathrm{io}}\right)$ and initial interparticular porosity $\left(\varepsilon_{\mathrm{eo}}\right)$ $\left(\varepsilon_{\mathrm{o}}=\varepsilon_{\mathrm{io}}+\varepsilon_{\mathrm{eo}}\right)$.

* $\quad P$ (in $\mathrm{MPa}$ ): forming pressure varying during compaction experiment.

* $\varphi=\frac{\varepsilon_{i 0}}{\varepsilon_{i 0}+\varepsilon_{e 0}}$ (no unit), porosity coefficient which is a characteristic of the powder.

* $\quad k_{\mathrm{f}}\left(\right.$ in $\mathrm{MPa}^{-1}$ ): fragmentation coefficient representing the ability of the grain to break. An amount of closed pores will be converted to open pores as particles crack. A weak value (typically $k_{\mathrm{f}}<10^{-4} \mathrm{MPa}^{-1}$ ) corresponds to grains that cannot easily break.

* $k_{\mathrm{CN}}$ (in $\mathrm{MPa}^{-1}$ ): plastic deformation coefficient representing the capacity of particles to undergo plastic strain and to increase the contact surface area between particles. A weak value (typically $k_{\mathrm{CN}}<10^{-4} \mathrm{MPa}^{-1}$ ) corresponds to extremely hard grains.

* $\psi$ (in $\mathrm{MPa}^{-1}$ ): reorganisation coefficient expressing the rate of pore volume elimination as pressure increases. It reveals the ability of granular systems to form ordered packings. A weak value (typically $\psi<10^{-3} \mathrm{MPa}^{-1}$ ) corresponds to a granular system that cannot be easily rearranged.

\section{Results and discussion}

\section{Main stress peak obtained in HVC experiments}

Fig. 6 gives the value of the main stress peaks obtained for each powder tested in HVC. We can see that adding more organic phase in the powder leads to a decrease of the principal stress peak. The nature of organic phase has an influence on the value of the stress peak. The softer formulation (PEG4Ooo only) gives the higher values and the higher the binder content, the lower the stress peak. For a given formulation, the finer the powder, the lower the stress peak.

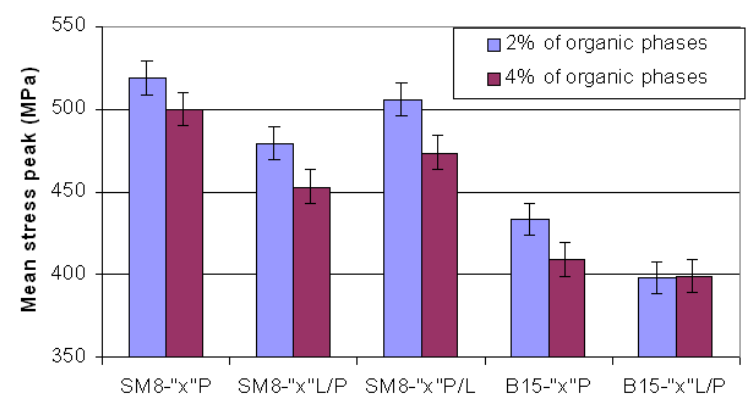

Fig. 6. Main HVC stress peak obtained for different formulations.

\section{Specific stored energy}

The specific stored energy at $400 \mathrm{MPa}$ can be obtained for each of the two forming methods. Fig. 7 shows the results obtained, except for SM8-2P that suffered from a lack of mechanical strength. 


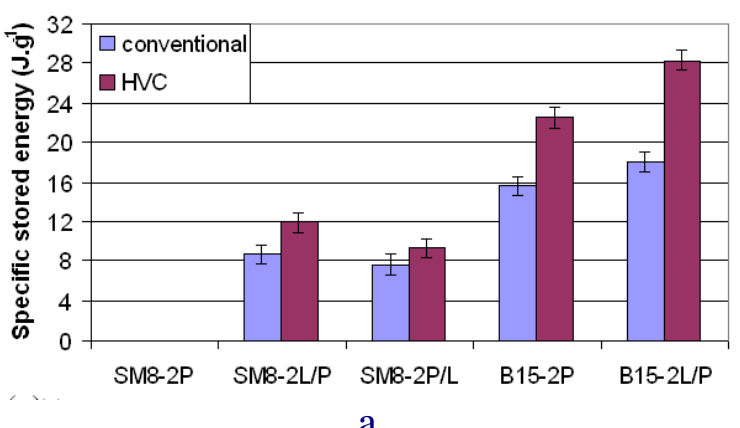

a

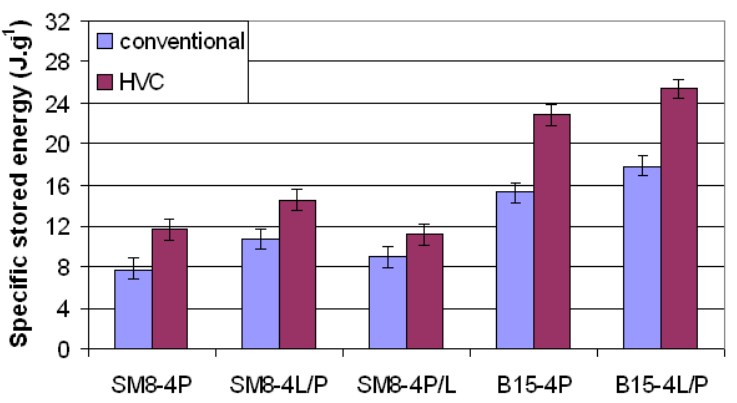

$\mathrm{b}$

Fig. 7: Specific stored energy at 400 MPa for each powder and for each forming methods, (a) Powders with $2 \%$ of organic phases; (b) powders with $4 \%$ of organic phases.

Crystallite size has an important influence on the specific stored energy. As B15 alumina is finer, there is a greater contact surface area between grains with more friction effects and more energy supplied for powder rearrangement.

The nature and the amount of organic phase can influence the specific stored energy of a powder. The greater the amount of plasticizer in the organic phase, the lower the specific stored energy. Increasing the amount of a given organic phase causes an increase of specific stored energy, but this result is true only for SM8 alumina. It seems that friction effects in B15 alumina prevails over the effect of the amount of organic phase.

For HVC compacts, the specific stored energy is $30 \%$ greater than their conventional homologues.

Remembering that the specific stored energy for HVC compact $s$ is calculated as if they had been formed at 400 Mpa. Fig. 8 shows the main stress peak obtained in HVC experiments as a function of specific stored energy as if tablets were formed at a pressure of $400 \mathrm{MPa}$.

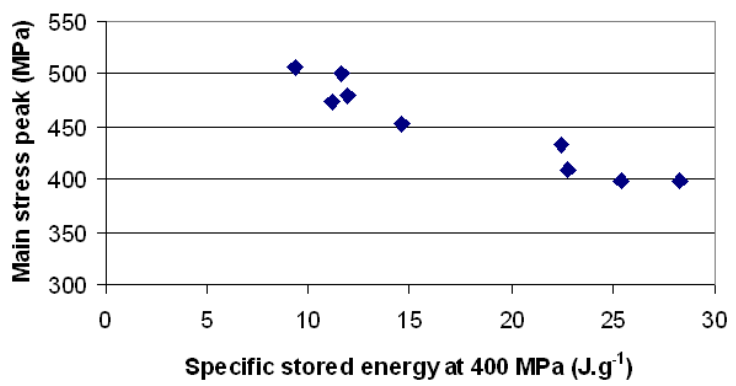

Fig.8: HVC main stress peak as a function of specific stored energy at $400 \mathrm{MPa}$

For all HVC experiments, $70 \mathrm{~g}$ of powder were impacted with the same energy. Fig. 8 shows that the less able a powder is to store energy, the higher is the main stress peak. For example, the SM8-2P/L powder needs less energy stored to reach a pressure of $400 \mathrm{MPa}$. The excess strike energy will make it possible to reach a pressure greater than $400 \mathrm{MPa}$. For B15-4 L/P powders, more energy has been stored, and there was enough energy available for reaching a $400 \mathrm{MPa}$ pressure under HVC conditions.

\section{Mechanical resistance}

The mechanical resistance of conventional compacts has been measured. These tests have not been performed on HVC compacts because the Brazilian test device was not powerful enough to break $50 \mathrm{~mm}$ diameter compacts. Fig. 9 gives the mechanical resistance (in $\mathrm{MPa}$ ) of conventional compacts made with the different powders.

Increasing the amount of organic phase in the powder leads to an enhancement of mechanical resistance due to an increase of grain-organic phase contacts. The greater is the amount of plasticizer, the worse is the mechanical resistance, because the organic phase softens the mixture.

The mechanical resistance of compacts formed with the $\mathrm{B} 15-2 \mathrm{~L} / \mathrm{P}$ powder is greater than that of compacts formed with the SM8-2L/P powder. 


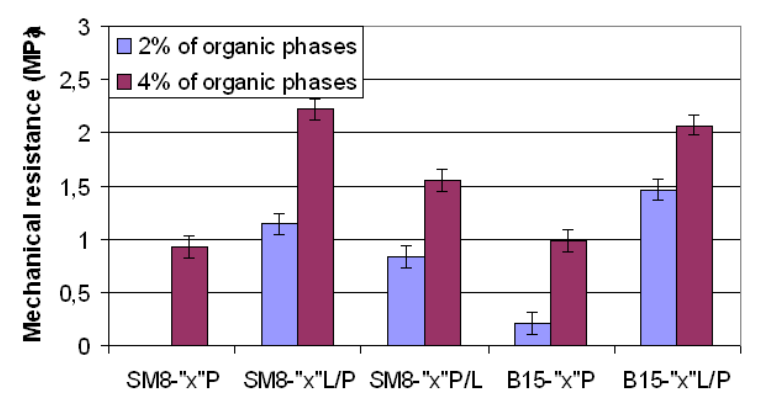

Fig.9: Mechanical resistance of conventional compacts.

A tablet formed with B15 alumina has more grain-grain contacts per unit of volume than the SM8 tablets. So, in B15 alumina, grain-grain contact areas are larger and more difficult to break. For lower amounts of organic phase, grain-grain contacts govern the mechanical resistance of B15 tablets. In the case of B15 alumina with $4 \%$ of organic phase, mechanical resistance is as great as its homologue with SM8 alumina. There are more grain-organic phase contacts and effects due to surface contact are inhibited.

Fig. 10 shows the mechanical resistance as a function of specific stored energy for conventional compacts. The mechanical resistance is linearly linked to the specific stored energy, as noticed by Guyot et al. [19]. To obtain a given mechanical resistance, a B15 alumina powder needs more energy than a SM8 powder. This also means that a B15 compact is more difficult to obtain.

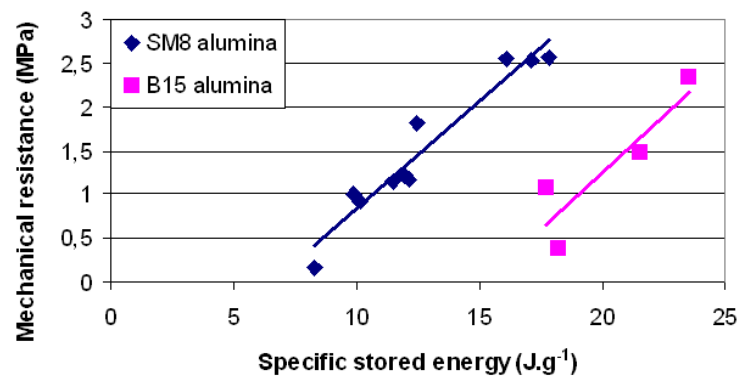

Fig 10: Mechanical resistance of conventional compacts as a function of their specific stored energy.

As the specific energy v in HVC compacts is 30\% greater than their conventional homologues, one may suppose that HVC compacts have a better mechanical resistance and that they can be manufactured more easily.

\section{Comparison of green density of compacts}

Conventional and HVC compacts are heated at $600{ }^{\circ} \mathrm{C}$ to burn out the organic phase. After this debinding cycle, the green density of compacts is measured and the influence of the amount and the nature of organic phases can be studied. Fig. 11 shows the results concerning green density of HVC and conventional compacts.
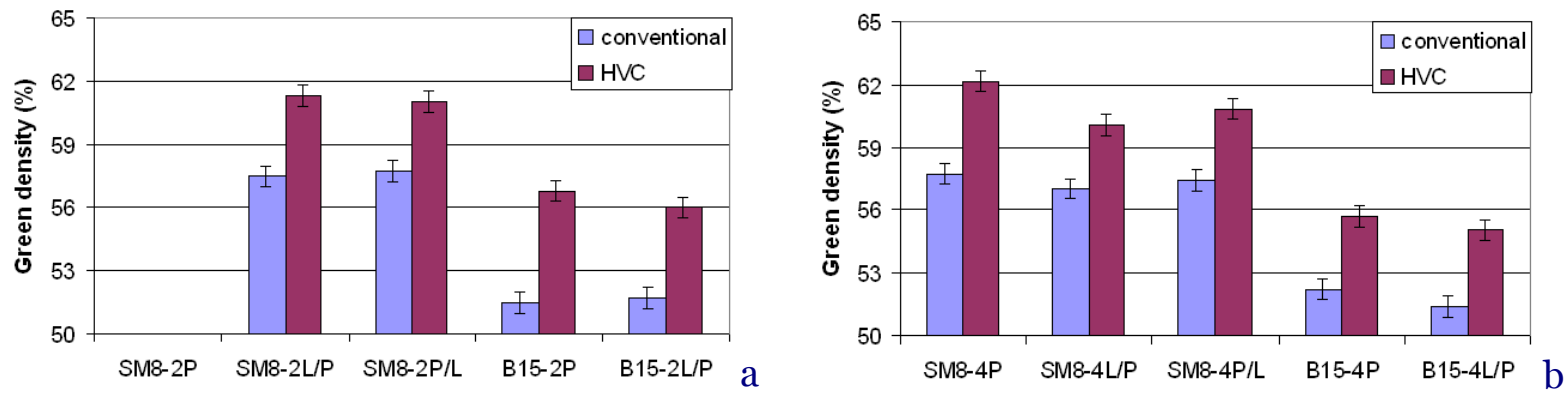

Fig. 11: Green density of HVC and conventional compacts (a) with 2\% of organic phases; (b) with 4\% of organic phases. 
Compacts formed with B15 alumina (finer) are less dense than identically formulated compacts formed with SM8 alumina. This phenomenon can be attributed to the greater friction effects in B15 alumina, which limits the grain rearrangement.

For compacts formed with SM8 powder, the nature of the organic phases has an influence on the green density. Increasing the amount of binder in the organic phase causes a decrease of the green density of compacts. Binders harden the organic phase, so a spray-dried powder appears more difficult to deform and a worse green density is obtained. Debinded compacts including $4 \%$ of a given formulation are less dense than debinded compacts having $2 \%$ of the same formulation: as more organic phases are burn, there are more pore volumes left in the compact.

HVC compacts are globally $7 \%$ more dense than their conventional homologues. As suggested by the results in Fig. 6 one would assume that enhanced green densities are due to the greater forming pressure. But in the case of B15 alumina, the HVC forming pressure is close to $400 \mathrm{MPa}$, so at equivalent forming pressure, HVC compacts densities are higher than their conventional homologues.

\section{Pore size distribution from MIP}

Fig. 12 shows the pore size distributions obtained with HVC and conventional debinded tablets formed with SM8-4L/P and B15-4L/P powders.

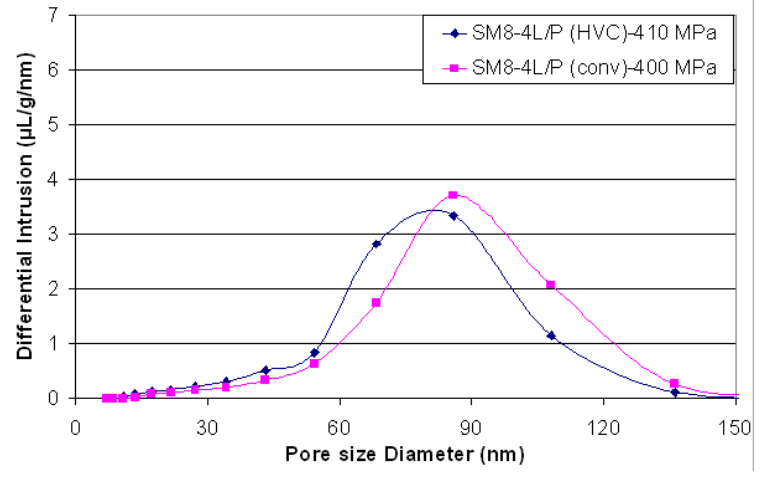

a

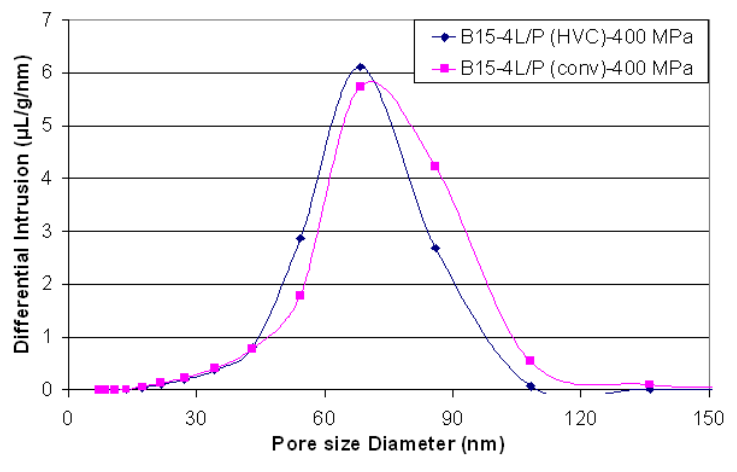

$\mathrm{b}$

Figure 12: Pore size distribution comparison of conventional and HVC tablets formed with (a) SM8$4 L / P$ and (b) B15-4L/P powders: influence of forming process and alumina crystallite size.

In the case of conventional tablets, the pore diameter associated to the maximum differential intrusion is $90 \mathrm{~nm}$ for SM8 alumina and $70 \mathrm{~nm}$ for B15 alumina. But for HVC compacts, formed at the same pressure, the corresponding maximum of pore size distribution is shifted to 75 and $65 \mathrm{~nm}$ respectively. This phenomenon can be attributed to a noticeable temperature increase $\left(>15{ }^{\circ} \mathrm{C}\right)$ of tablets before and after HVC experiments, making possible further rearrangements in the formulated powder under compaction.

\section{Quasi-chemical model}

The quasi-chemical model has been used to estimate at what intensity do fragmentation, plastic deformation and rearrangement phenomena occur. In this study, organic phases have been taken into account for density and porosity calculations.

The initial porosity $\left(\varepsilon_{0}\right)$ of all powders has been previously determined. $\varphi, k_{\mathrm{f}}, k_{\mathrm{CN}}$ and $\psi$ are determined by a least squares method so that theoretical porosity for a given pressure is equal to experimental porosity for this same pressure. Because of the $60 \mathrm{MPa}$ precompression, least squares method is applied from $60 \mathrm{MPa}$ to the highest pressure and the $\varepsilon_{0}$ value is imposed for the o MPa pressure.

After analyses of all compacts (conventional and $\mathrm{HVC}$ ), it is found that $k_{\mathrm{f}}$ and $k_{\mathrm{CN}}$ have a value near $10^{-3} \mathrm{MPa}^{-1}, \psi$ is close to $10^{-1} \mathrm{MPa}^{-1}$ and $\varphi$ value is always greater than 0.27 .

If we consider that $k_{\mathrm{f}}$ and $k_{\mathrm{CN}}$ are negligible with respect to $\psi$, the quasi-chemical model equation giving the relationship between the porosity $\varepsilon$ and pressure $P$ can be simplified and becomes: 


$$
\frac{\varepsilon}{1-\varepsilon}=\frac{\varepsilon_{0}}{1-\varepsilon_{0}} \cdot\left[\varphi \cdot e^{-\left(k_{f}+k_{C N}\right) \cdot P}+(1-\varphi) \cdot e^{-\psi \cdot P}\right]
$$

It can be seen that fragmentation and plastic deformation cannot be studied separately, so, for the powders studied here, the compaction phenomenology is based on $\varphi, \psi$ and $k_{\mathrm{f}}+k_{\mathrm{CN}}$ sum. Table 2 gives the values of the coefficients for each powder and for each forming method and also the correlation coefficient $\left(R^{2}\right)$.

Table 2: Coefficients obtained with the quasi-chemical model applied to HVC and conventional compacts (values in $\mathrm{MPa}^{-1}$ except $\varepsilon, \varepsilon_{o}, R^{2}$ and $\varphi$ dimensionless)

\begin{tabular}{|c|c|c|c|c|c|c|c|c|c|c|}
\hline & \multicolumn{5}{|c|}{ Conventional } & \multicolumn{5}{|c|}{ HVC } \\
\hline & $\begin{array}{l}\text { SM8- } \\
2 \mathrm{P}\end{array}$ & $\begin{array}{l}\text { SM8- } \\
2 \mathrm{~L} / \mathrm{P}\end{array}$ & $\begin{array}{l}\text { SM8- } \\
\text { 2P/L }\end{array}$ & $\begin{array}{l}\mathrm{B} 15^{-} \\
2 \mathrm{P}\end{array}$ & $\begin{array}{l}\mathrm{B} 15^{-} \\
2 \mathrm{~L} / \mathrm{P}\end{array}$ & $\begin{array}{c}\text { SM8- } \\
2 \mathrm{P}\end{array}$ & $\begin{array}{l}\text { SM8- } \\
2 \mathrm{~L} / \mathrm{P}\end{array}$ & $\begin{array}{l}\text { SM8- } \\
2 \mathrm{P} / \mathrm{L}\end{array}$ & $\begin{array}{l}\mathrm{B} 15^{-} \\
2 \mathrm{P}\end{array}$ & $\begin{array}{l}\mathrm{B} 15^{-} \\
2 \mathrm{~L} / \mathrm{P}\end{array}$ \\
\hline$\varepsilon_{0}$ & - & 0.731 & 0.738 & $\begin{array}{c}0.72 \\
3\end{array}$ & 0.771 & - & 0.759 & 0.758 & $\begin{array}{c}0.74 \\
2\end{array}$ & 0.794 \\
\hline$\varphi$ & - & 0.275 & 0.258 & $\begin{array}{c}0.40 \\
3\end{array}$ & 0.312 & - & 0.291 & 0.277 & $\begin{array}{c}0.39 \\
2\end{array}$ & 0.378 \\
\hline $\begin{array}{l}\mathrm{k}_{\mathrm{f}}+ \\
\mathrm{k}_{\mathrm{CN}}\end{array}$ & - & $\begin{array}{c}6.92 .1 \\
0^{-4}\end{array}$ & $\begin{array}{c}6.50 .1 \\
0^{-4}\end{array}$ & $\begin{array}{c}9.83 . \\
10^{-4}\end{array}$ & $\begin{array}{c}1.11 .10 \\
-3\end{array}$ & - & $\begin{array}{c}1.15 .10^{-} \\
3\end{array}$ & $\begin{array}{c}1.19 .10 \\
-3\end{array}$ & $\begin{array}{c}1.44 . \\
10^{-3}\end{array}$ & $\begin{array}{c}1.99 .1 \\
0^{-3}\end{array}$ \\
\hline$\psi$ & - & 0.055 & 0.062 & $\begin{array}{c}0.04 \\
9\end{array}$ & 0.047 & - & 0.062 & 0.107 & $\begin{array}{c}0.06 \\
2\end{array}$ & 0.134 \\
\hline $\mathrm{R}^{2}$ & - & 0.974 & 0.978 & $\begin{array}{c}0.98 \\
4\end{array}$ & 0.989 & - & 0.973 & 0.986 & $\begin{array}{c}0.99 \\
6\end{array}$ & 0.991 \\
\hline & $\begin{array}{c}\text { SM8- } \\
4 \mathrm{P}\end{array}$ & $\begin{array}{l}\text { SM8- } \\
4 \mathrm{~L} / \mathrm{P}\end{array}$ & $\begin{array}{l}\text { SM8- } \\
4 \mathrm{P} / \mathrm{L}\end{array}$ & $\begin{array}{l}\mathrm{B} 15^{-} \\
4 \mathrm{P}\end{array}$ & $\begin{array}{l}\mathrm{B} 15^{-} \\
4 \mathrm{~L} / \mathrm{P}\end{array}$ & $\begin{array}{c}\text { SM8- } \\
4 \mathrm{P}\end{array}$ & $\begin{array}{l}\text { SM8- } \\
4 \mathrm{~L} / \mathrm{P}\end{array}$ & $\begin{array}{l}\text { SM8- } \\
4 \mathrm{P} / \mathrm{L}\end{array}$ & $\begin{array}{l}\mathrm{B} 15^{-} \\
4 \mathrm{P}\end{array}$ & $\begin{array}{l}\mathrm{B} 15^{-} \\
4 \mathrm{~L} / \mathrm{P}\end{array}$ \\
\hline$\varepsilon_{0}$ & 0.643 & 0.723 & 0.713 & $\begin{array}{c}0.69 \\
5\end{array}$ & 0.754 & 0.694 & 0.752 & 0.750 & $\begin{array}{c}0.72 \\
5\end{array}$ & 0.779 \\
\hline$\varphi$ & 0.348 & 0.266 & 0.273 & $\begin{array}{c}0.37 \\
7\end{array}$ & 0.308 & 0.369 & 0.280 & 0.285 & 0.411 & 0.320 \\
\hline $\begin{array}{l}\mathrm{k}_{\mathrm{f}}+ \\
\mathrm{k}_{\mathrm{CN}}\end{array}$ & $\begin{array}{c}7.66 .1 \\
0^{-4}\end{array}$ & $\begin{array}{c}8.55 .1 \\
0^{-4}\end{array}$ & $\begin{array}{c}8.81 .10 \\
-4\end{array}$ & $\begin{array}{l}1.01 . \\
10^{-3}\end{array}$ & $\begin{array}{c}1.09 .1 \\
0^{-3}\end{array}$ & $\begin{array}{c}1.74 .1 \\
0^{-3}\end{array}$ & $\begin{array}{c}1.49 .10 \\
-3\end{array}$ & $\begin{array}{c}1.58 .10 \\
-3\end{array}$ & $\begin{array}{c}1.94 . \\
10^{-3}\end{array}$ & $\begin{array}{c}1.90 .1 \\
0^{-3}\end{array}$ \\
\hline$\psi$ & 0.055 & 0.045 & 0.068 & $\begin{array}{c}0.03 \\
7\end{array}$ & 0.041 & 0.173 & 0.153 & 0.202 & $\begin{array}{c}0.24 \\
4\end{array}$ & 0.153 \\
\hline $\mathrm{R}^{2}$ & 0.980 & 0.985 & 0.978 & $\begin{array}{c}0.98 \\
8\end{array}$ & 0.974 & 0.985 & 0.980 & 0.966 & $\begin{array}{c}0.99 \\
0\end{array}$ & 0.992 \\
\hline
\end{tabular}

The data shows that powders formulated with only PEG400o (SM8-4P, B15-2P and B15-4P) exhibit the highest $\varphi$ values. This means that the initial interparticular porosity in these powders is less important. This is probably due to the filling of intergranular pores of alumina powders by PEG4000. In the case of B15 alumina, $\varphi$ value is higher than with a SM8 alumina with the same formulation, i.e. intraparticular porosity is more important in B15 than SM8 powder. For HVC compacts, $\varphi$ mean value is $5 \%$ higher. We estimate that this result is due to wall effects that locally increase $\varepsilon_{0}$ along the wall of the die $(\varnothing=20 \mathrm{~mm}$ in conventional, $\varnothing=50 \mathrm{~mm}$ in HVC). The amount of organic phase does not have a significant influence on $\varphi$ value.

For conventional compacts, the reorganisation coefficient $(\psi)$ does not vary significantly with the amount of organic phase. However, the nature of organic phase seems to present a strong influence. The increase of binder amount in the organic formulation causes a decrease of the $\psi$ value. Hardening the organic phase interferes with the granular rearrangement and it is more difficult to eliminate porosity. For compacts formed with a B15 alumina, the value of $\psi$ is less than that obtained with a SM8 alumina formulated in the same way. Friction effects due to the smaller crystallite size make granular rearrangements more difficult.

The value of $\psi$ for a HVC compact formed with a powder with $2 \%$ of organic phases is slightly greater than the value of its conventional homologue. But for powders formulated with $4 \%$ of 
organic phases, the value of $\psi$ for HVC compacts is four times greater than their conventional homologues. The increase of the amount of organic phases makes the grain rearrangements easier. This is due to a conversion of a part of the energy supplied to thermal energy (as noticed by Bondar [8] and Wolf et al. [11]). This effect enhances the viscous characteristic of the organic phase and allows denser packing. HVC is efficient for obtaining dense compacts if the amount of organic phases is sufficient.

For conventional compacts, the sum $k_{\mathrm{f}}+k_{\mathrm{CN}}$ is not really influenced by the nature of organic phases, but increasing the amount of organic phase leads to an increase of $k_{\mathrm{f}}+k_{\mathrm{CN}}$, meaning that fragmentation or plastic deformation phenomena are favoured. The sum $k_{\mathrm{f}}+k_{\mathrm{CN}}$ is greater with a finer alumina. For HVC compacts, the same trends are observed, but the $k_{\mathrm{f}}+k_{\mathrm{CN}}$ values are twice as big as in the conventional case.

As the model only gives the sum $k_{\mathrm{f}}+k_{\mathrm{CN}}$, we used SEM to observe rupture facieses of conventional and HVC compacts in order to identify the relative importance of fragmentation and plastic deformation. Photographs are shown in Fig. 13.

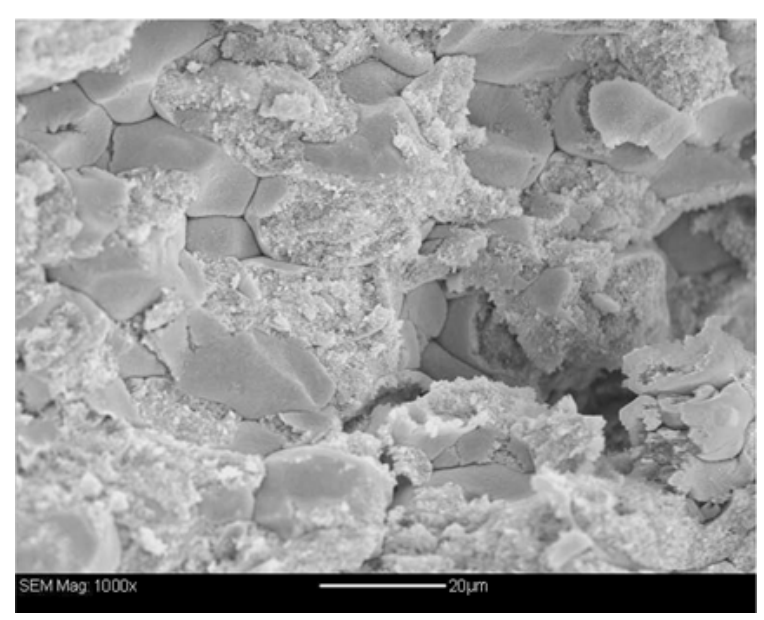

a

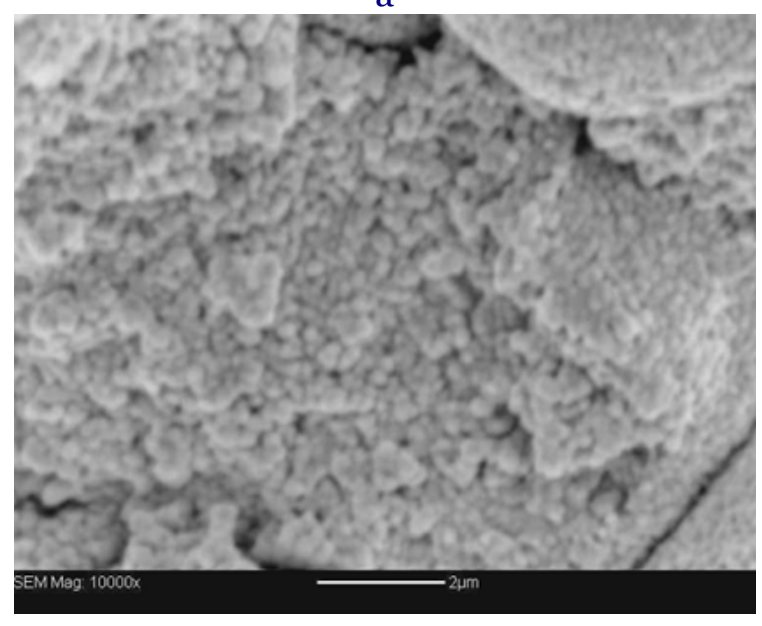

c

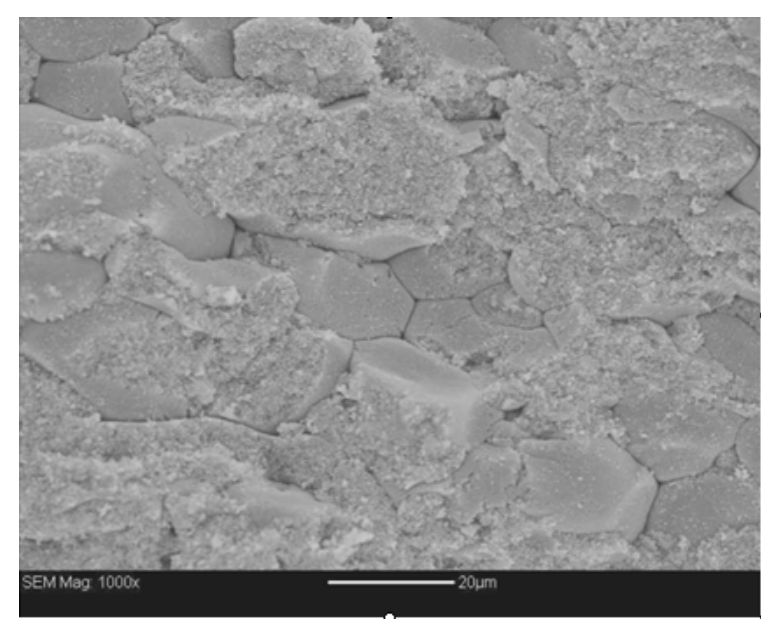

$\mathrm{b}$

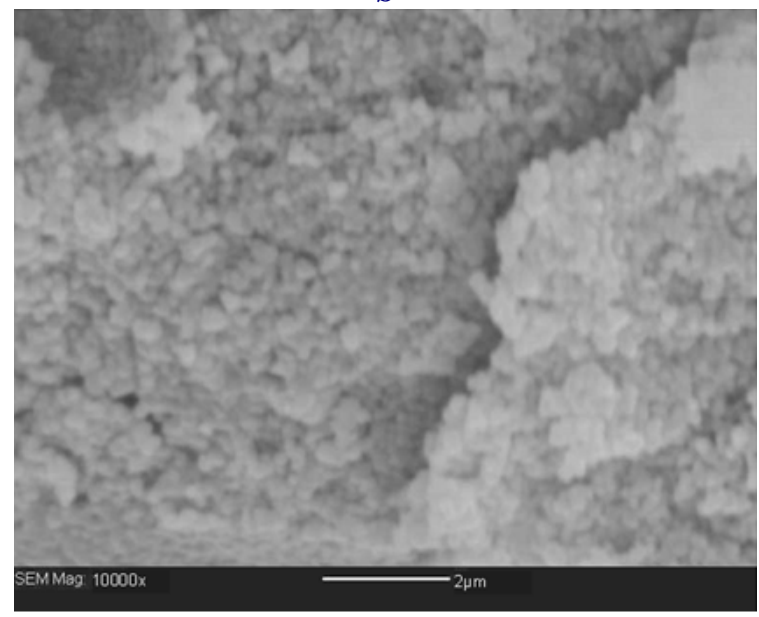

$\mathrm{d}$

Figure 13: SEM photographs of rupture facieses of compacts focused on (a) conventional spray-dried particles, (b) HVC spray-dried particles, (c) conventional crystallites, (d) HVC crystallites.

The photographs (a) and (b) show that spray-dried particles tend to deform plastically and not to break, whereas the photographs (c) and (d) show that crystallites are neither deformed nor broken. Finally, such results suggest that compaction in this study is governed mainly by plastic deformation of spray-dried granules and $k_{\mathrm{f}}<<k_{\mathrm{CN}}$.

Fig. 14 is obtained by using model data. It represents the pressure-density curve of a SM84L/P powder compacted by HVC or conventional pressing. 


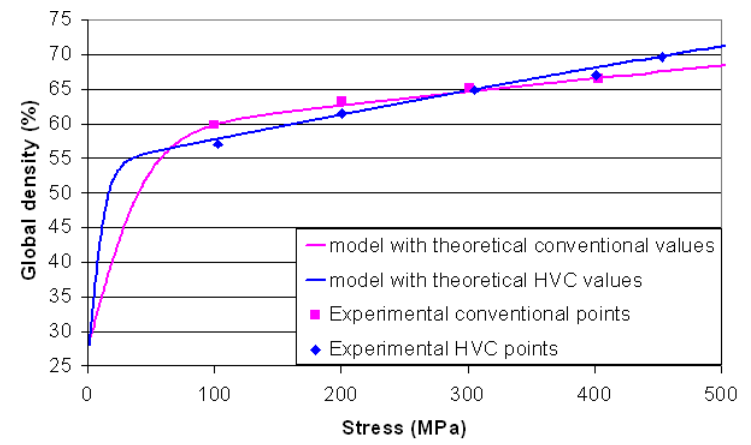

Fig 14: Theoretical pressure-density curve and experimental points for SM8-4L/P powder compacted by HVC or conventional pressing.

The model fits the experimental data very well. At the beginning of compaction, a HVC compact is denser than its conventional homologue, due to a better reorganisation. Beyond approximately $80 \mathrm{MPa}$, the conventional compact is denser and when a $300 \mathrm{MPa}$ pressure is reached, a HVC compact exhibits a better density. HVC leads to better compacts if a pressure threshold is reached.

\section{Conclusions}

The compaction behaviour of a spray-dried alumina powder depends on the formulation of its organic binder, its crystallite size and the forming method.

For quasi-static uniaxial pressing, organic formulations based only on plasticizers lead to dense compacts with a poor mechanical resistance. The incorporation of a binder hardens the organic phase, so that the compacts obtained are less dense but more resistant.

A process called High Velocity Compaction has been applied to alumina powder resulting in compacts denser than conventional ones with a finer pore size distribution (for an identical forming pressure).

The pore size distribution (PSD) of tablets is shifted towards lower values when small grain particles are used, whatever the conventional or HVC method. For a powder of a given particle size, the conventional compact presents a PSD at higher values than for HVC. This phenomenon can be attributed to a noticeable rise in temperature during HVC experiments, making possible further rearrangements in the powder under compaction.

The use of the quasi-chemical model allowed us to compare compaction phenomenology between these two forming methods. The compaction behaviour of the formulated spraydried alumina is mainly based on plastic deformation of granules. This phenomenon is more important in HVC when the amount of organic phase is important. Moreover, the pore elimination rate is greater in HVC and tends to be favoured by large amounts of organic phase. Above a given pressure, HVC compacts are definitely denser than conventional ones. Finally, compared to conventional pressing, HVC leads to larger, denser and potentially more resistant alumina pieces if the amount of organic phase is sufficient. Further investigations must be carried out to clearly understand the role of the organic phase, and computer simulations with finite or discrete elements should bring a clarification on rearrangement mechanisms.

\section{Acknowledgement}

We acknowledge the French Rhône-Alpes Region for the financial support of this study.

\section{REFERENCES}

[1] H. Kim, O. Gillia, D. Bouvard, A Phenomenological Constitutive Model For the Sintering of Alumina Powder, Journal of European Ceramic Society 23 (10) (2003) 1675-1685.

[2] W.T. Montgomery, H. Thomas, The Compacting of Metal Powders by Explosives, Powder Metallurgy 6 (1960) 125-128. 
[3] E. La Rocca, J. Pearson, Explosive Press for Use in Impulsive Loading Studies, Review of Scientific Instruments 29 (10) (1958) 848-851.

[4] R.J. Brejcha, High Density Metal Powder Compaction by Means of a Cartridge Actuated Press, Engineer's Digest 23 (7) (1962) 77.

[5] E.M. Stein, J.R. Van Orsdel, P. V. Schneider, High Velocity Compaction of Iron Powder, Metal Progress 85 (4) (1964) 83-86.

[6] G.Geltman, Explosive Compacting of Metal Powders, New Methods For The Consolidation of Metal Powders, Plenum Press (1967) 75.

[7] S. Wang, R. Davies, Some Effects of High Speeds on Metal Powder Compaction, Proc. 9th International Machine Tool Design and Research Conference, Birmingham, 1968 (Pergamon).

[8] M. P. Bondar, explosive compaction : the type of microstructure of contact boundaries produces by formation of a strong bond, Combustion, explosion and shock waves 40 (4) (2004) 489-497.

[9] P. Goeuriot, A. Girinon, Compaction dynamique grande vitesse de poudres céramiques. Conséquences sur les microstructures des produits frittés, Colloque « De la poudre au matériau massif », Albi, 3-5/06/2003.

[10] T. Erhart, W. A. Wall, E. Ramm, A robust computational approach for dry powders under quasi-static and transient impact loadings, Comput. Methods Appl. Mech. Engrg. 194 (2005) 4115-4134.

[11] D. E. Wolf, T. Unger, D. Kadau, L. Brendel, compaction of cohesive powders, powder and grains, eds. R. Garcia Rojo, H. J. Herrmann, S. Mc Namara (Balkema Leiden) (2005) 525-532.

[12] B. Azhdar, B. Stenberg, L. Kari, Development of a High-Velocity Compaction process for polymer powders, polymer testing 24 (2005) 909-919.

[13] G. Sethi, E. Hauck, R. M. German, High velocity compaction compared with conventional compaction, Materials Science and Technology 22 (8) (2006) 955-959.

[14] J.G. Auret, I. Sigalas, A. I. Kingon, high pressure compaction of alumina powders, American ceramic society bulletin 65 (9) (1986) 1301-1305.

[15] S. Baklouti, T. Chartier, J. F. Baumard, Binder distribution in spray-dried alumina agglomerates, journal of the european ceramic society 18 (1998) 2117-2121.

[16] D. Chulia, M. Deleuil, Y. Pourcelot, powder technology and pharmaceutical processes 9, elsevier, Amsterdam (1994) 406-408.

[17] M. Dürr, D. Hanssen, H. Harwalik, Kennzahlen zur Beurteilung der Verpreßbarkeit von Pulvern und Granulaten, Pharm. Ind. 34 (11) (1972) 905-911.

[18] A. Stamm, C. Mathis, Étude de la comprimabilité de différents excipients pour compression directe, R. Sci. Techn. Pharma. 5 (5) (1976) 245-253.

[19] J. C. Guyot, A. Delacourte, B. Devise, M. Traisnel, optimisation en technologie de compression, labo. Pharma., problèmes techniques 263 (1977) 209-214.

[20] M. G. Vachon, D. Chulia, the use of energy indices in estimating powder compaction functionality of mixtures in pharmaceutical tableting, International Journal of pharmaceutics 177 (1999) 183-200.

[21] J. Fell, J.M. Newton, Determination of tablet strength by diametral-compression test, Journal of Pharmaceutical Sciences 59 (5) (1970) 688-691.

[22] J. M. Sonnergaard, investigation a new mathematical model for compression of pharmaceutical powders, European Journal of Pharmaceutical Sciences 14 (2001) 149-157.

[23] Y. Gonthier, D. Chulia, Contrôle de qualité et formulation, S.T.P. pharma. 2 (1986) 221-228.

[24] P. Lamy, G. Thomas, L. Brunet, R. Erre, Modelling the porosity evolution of a powder under uniaxial compression, Propellants, Explosives, Pyrotechnics 30 (6) (2005) 397-403. 